\title{
First example of ring carbo-mer of 1,4-cyclohexadiene
}

Cécile Barthes $^{\mathrm{a}}$, Arnaud Rives ${ }^{\mathrm{a}}$, Valérie Maraval ${ }^{\mathrm{a}^{*}}$, Evelyne Chelain ${ }^{\mathrm{b}}$, Thierry Brigaud ${ }^{\mathrm{b}}$, Remi Chauvin $^{\mathrm{a}^{*}}$

${ }^{\text {a }}$ CNRS, LCC (Laboratoire de Chimie de Coordination), 205 route de Narbonne, BP 44099, F31077 Toulouse Cedex 4, France

Université de Toulouse, UPS, ICT-FR 2599, 31062 Toulouse Cedex 9, France. valerie.maraval@lcc-toulouse.fr, chauvin@lcc-toulouse.fr

${ }^{\mathrm{b}}$ EA 4505, LCB (Laboratoire de Chimie Biologique), 5 mail Gay Lussac - Neuville sur Oise, F-95031 Cergy Pontoise Cedex, France

Keywords: butatrienes, carbo-cyclohexadienes, carbo-mers, nucleophilic trifluoromethylation.

While a series of carbo-mers of 1,3-cyclohexadienes was reported through the use of a specifically developed synthetic strategy, no example of their 1,4-regioisomers was known. Inspired by the methodology elaborated for the preparation of the 1,3-isomers, the synthesis of the first example of carbo-mer of 1,4-cyclohexadiene is presented. Comparison of physico-chemical properties of this first representative with those of the recently described 1,3-regioisomer, especially UV-vis absorption properties, is also addressed.

\section{Introduction}

The first example of carbocyclohexadiene $\mathbf{1}$, reported in 2012 [1,2], resulted from an incomplete reduction of a [6]pericyclynic precursor 2 of the corresponding para-dianisyl-carbo-benzene original target $\mathbf{3}$ $[3,4]$. The conjugated ring carbo-mer of 1,3cyclohexadiene $\mathbf{1}$ was the sole sub-reduced product separated from the reaction mixture by semi-preparative HPLC, without evidence of non-conjugated 1,4-isomers 4 or 5 (Scheme 1). Since then, a series of bis-trifluoromethylated conjugated carbo-1,3-cyclohexadienes $\mathbf{1 F}$ was developed on the basis of a synthesis procedure involving bis-trifluoromethylated [6]pericyclynic precursors of type 2F (Scheme 2) [5].

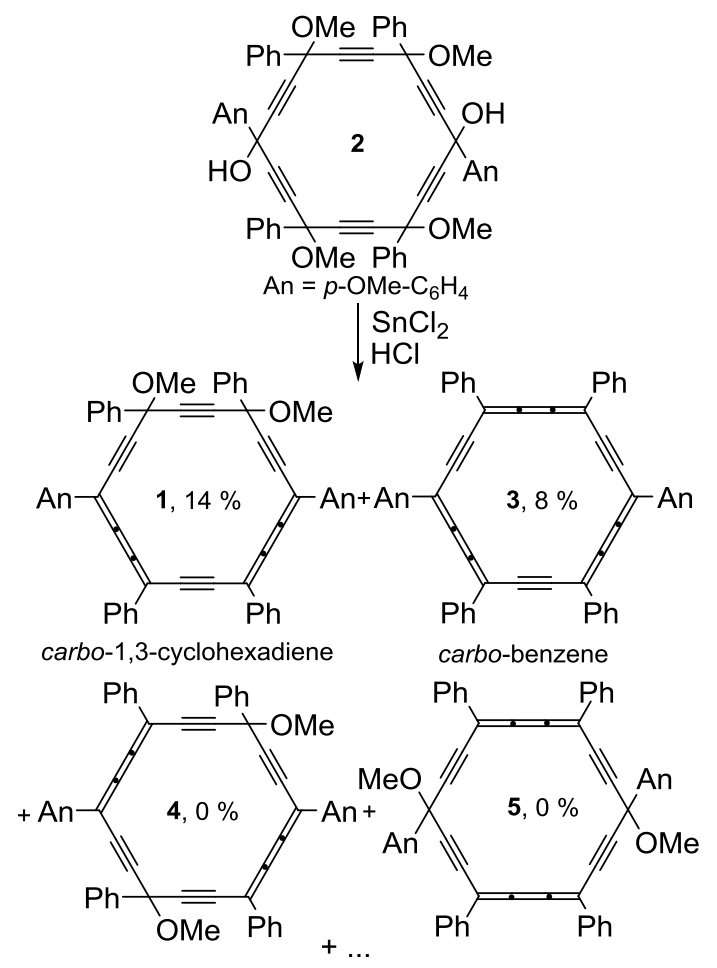

Scheme 1. First isolation in the tetraphenyl-dianisyl series of a carbo-mer of 1,3-cyclohexadiene 1, sub-reduction side-product of the [6]pericyclynediol 2 to the carbobenzene 3 [1]. 
The two trifluoromethyl groups of $\mathbf{2 F}$, replacing two phenyl groups of $\mathbf{2}$, at two adjacent vertices allowed the selective fourelectron reduction to the carbo-cyclohexadiene target $\mathbf{1 F}$, through the destabilization of the carbenium intermediate possibly generated by the acidic character of the reducing $\mathrm{SnCl}_{2} / \mathrm{HCl}$ system [6].

The carbo-mers of 1,3-cyclohexadienes $\mathbf{1}$ and $\mathbf{1 F}$, isolated as cis/trans diastereoisomeric mixtures, were found to be stable chromophores, some of them exhibiting the rare property of dichromism in solution $[1,5,7]$.

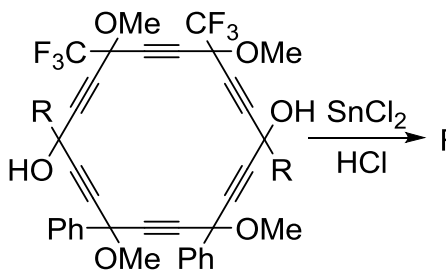

2F: $\mathrm{R}=\mathbf{a}: \mathrm{An}, \mathbf{b}: \mathrm{Ph}, \mathbf{c}: \mathrm{C}_{6} \mathrm{H}_{4}-\mathrm{CF}_{3}$, d: $\mathrm{C}_{6} \mathrm{H}_{4}$-Indole, e: $\mathrm{C}_{6} \mathrm{H}_{4}$-Carbazole

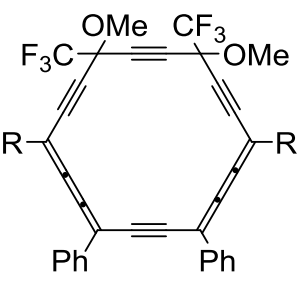

1F: $R=20-69 \%$

Scheme 2. Synthesis of bis-trifluoromethylated ring carbo-mers of 1,3-cyclohexadienes $\mathbf{1 F}$ [5]. An = Anisyl = $4-\mathrm{MeO}-\mathrm{C}_{6} \mathrm{H}_{4}$

The conjugated nature of the tetraphenylated carbo-mer of 1,3cyclohexadiene 1 was inferred by confrontation of the experimental UV-vis absorption spectrum, exhibiting two intense bands at 437 and $602 \mathrm{~nm}$, with calculated spectra at the ZINDO level, reproducing with high accuracy the two intense bands at 433 and $615 \mathrm{~nm}$ : the calculated spectrum of the 1,4-regioisomer 4 (Scheme 1) was indeed calculated to exhibit a completely different pattern, with a single intense band at $449 \mathrm{~nm}$ [1]. Nevertheless, carbo-mers of 1,4-cyclohexadienes with nonconjugated dialkynylbutatriene edges (DAB), such as 4 and 5 remain unknown (Scheme 1). Numerous chromophores containing isolated DAB motifs were however recently described, their stability varying significantly with the nature of the substituents $[8,6]$.

The first synthesis of a carbo-mer of 1,4cyclohexadiene, $\mathbf{6}$, is presented hereafter. Physico-chemical properties of $\mathbf{6}$ are then compared with both those of the 1,3-isomer $\mathbf{1 F b}$ and known acyclic DABs.

\section{Results and discussion}

The preparation of the carbocyclohexadiene 6 relies on a two-step strategy starting from the known [6]pericyclynedione 7 [3e], a key precursor for the synthesis of quadrupolar para-disubstituted carbo-benzenes $[4 d, f, g]$. In order to prevent the formation of two conjugated endocyclic butatriene edges, i.e. to orientate the reaction towards the formation of two butatriene moieties on two facing egdes of the $\mathrm{C}_{18}$ macrocycle, the two trifluoromethyl substituents were envisaged at opposite vertices (C1 and C10) (Scheme 3). It was indeed recently evidenced that trifluoromethyl substituents inhibit the dissociation of geminal hydroxy or methoxy group and subsequently the formation of a butatriene unit upon treatment with $\quad \mathrm{SnCl}_{2} / \mathrm{HCl} \quad[5,6]$. Trifluoromethyl 
substituents were anchored at the macrocycle using a known procedure consisting in the addition of the Ruppert-Prakash reagent $\mathrm{CF}_{3}$ TMS on the two carbonyl groups of 7 in the presence of CsF as initiator (Scheme 3) [9]. The putative bis-silylether intermediate was not isolated, but in situ hydrolyzed by treatment with aqueous $2 \mathrm{M} \mathrm{HCl}$. The resulting bistrifluoromethylated diol $\mathbf{8}$ was then reacted with $\mathrm{SnCl}_{2} / \mathrm{HCl}$ in DCM to afford the carbocyclohexadiene target $\mathbf{6}$, which was isolated as a red-orange solid in $6 \%$ yield. This first carbomer of 1,4-cyclohexadiene could be fully characterized by spectroscopic methods $\left({ }^{1} \mathrm{H}\right.$, ${ }^{13} \mathrm{C},{ }^{19} \mathrm{~F}$ NMR, IR, ...) but it was found to be much less stable than the 1,3-isomer $\mathbf{1 F b}$ (which was isolated in a higher yield of $20 \%$ ).

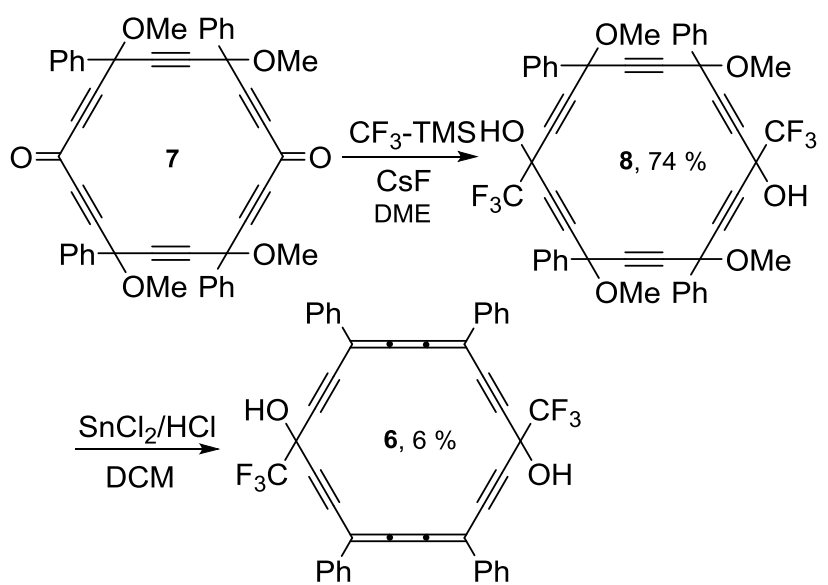

Scheme 3. First synthesis of a carbo-mer of 1,4cyclohexadiene $\mathbf{6}$, non-conjugated isomer of $\mathbf{1 F b}$ (Scheme 2).

The formation of $\mathbf{6}$ is evidenced by the disappearance of all the methoxy ${ }^{1} \mathrm{H}$ NMR signals of 8 at 3.40-3.65 ppm, accompanied by a simplification of the aromatic ${ }^{1} \mathrm{H}$ signals due to the decrease of the number of diastereoisomers (2 in $\mathbf{6} v s$ in 8) [3e].

In spite of the non-conjugated nature of the DAB edges, the carbo-cyclohexadiene 6 remains chromophoric, giving intense yellow solutions in usual organic solvents. The absorption spectrum, recorded in $\mathrm{CHCl}_{3}$ solution, exhibits one intense band at $\lambda_{\max }=418$ nm (Figure 1a). This UV-vis spectrum can be naturally compared with those of $\mathbf{9}$ containing a non-conjugated DAB motif, and of the carbocyclohexadiene conjugated isomer 1Fb (Figure 1b).
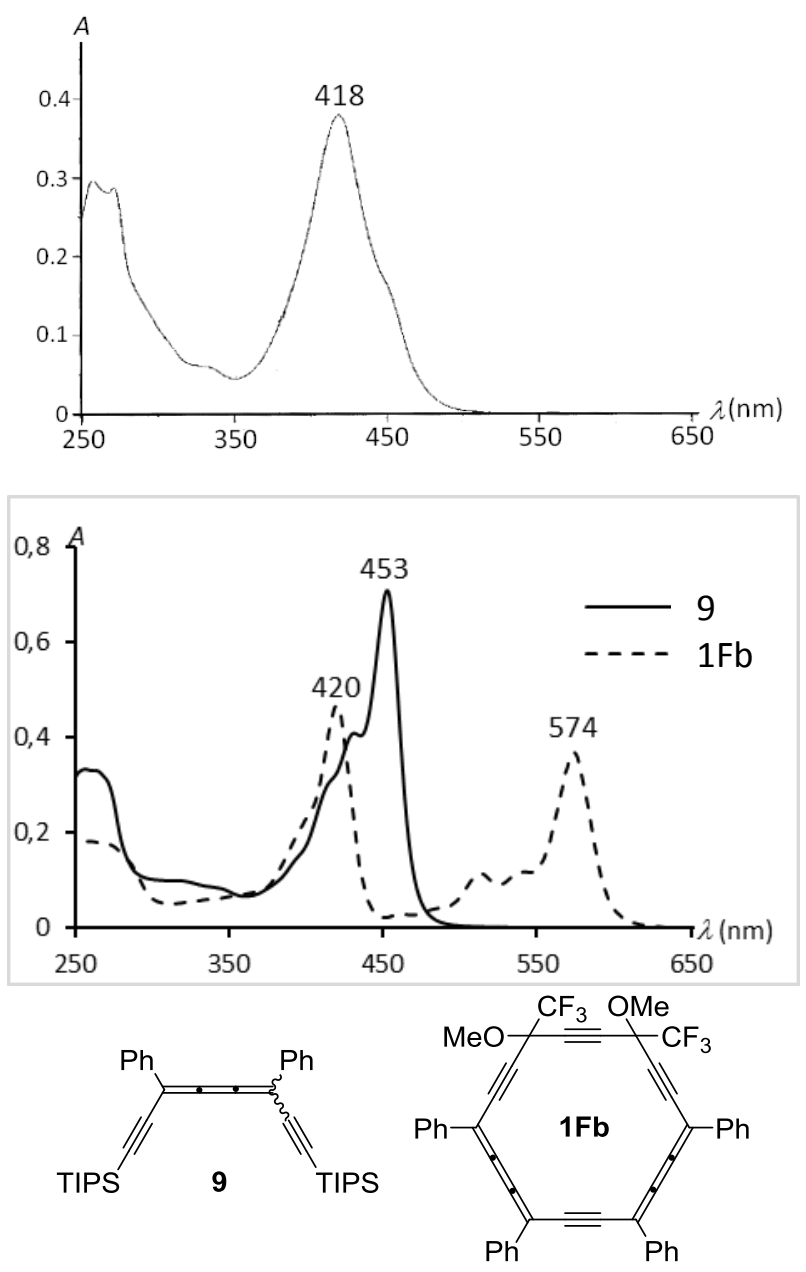

Figure 1. 1a. UV-vis spectrum of 6 (top); 1b. UV-vis spectra of the DAB 9 and carbo-cyclohexadiene 1Fb (bottom). Spectra recorded in $\mathrm{CHCl}_{3}$ solutions. 
conjugated systems and with previous semi

The one-band spectral profile of 6 resembles that of $\mathbf{9}$ and is reminiscent of the ZINDO-calculated spectrum of 4 (albeit at higher energy because the DAB motifs are not conjugated with the methoxy groups of the anisyl substituents). It is also completely different from the two-band profile of the conjugated isomer $\mathbf{1 F b}$ [5]. The hypsochromic shift of the $\lambda_{\max }$ value of $6(418 \mathrm{~nm})$ with respect to $9(453 \mathrm{~nm})$ is attributed to the withdrawing effect of the $\mathrm{CF}_{3}$ groups of $\mathbf{6}$. In the dibutatrienylacetylene (DBA) series, namely the carbo- $n$-butadienes, it was indeed observed that electron withdrawing substituents induce a relative hypsochromic shift [10]. Nevertheless, the two products exhibit comparable molar extinction coefficients of $\varepsilon_{6}=73400 \mathrm{~L} \cdot \mathrm{mol}^{-}$ ${ }^{1} . \mathrm{cm}^{-1}$ and $\varepsilon_{9}=53400 \mathrm{~L} \cdot \mathrm{mol}^{-1} \cdot \mathrm{cm}^{-1}$. It is remarkable that the $\lambda_{\max }$ value of $6(418 \mathrm{~nm})$ is almost identical to the first $\lambda_{\max }$ value of the conjugated isomer $\mathbf{1 F b}(420 \mathrm{~nm})$. Nevertheless, the second strong band of $\mathbf{1 F b}$ at $\lambda_{\text {max }}^{\prime}=574$ $\mathrm{nm}$ is correlated with the $\pi$-conjugation extension in 1Fb (over $14 \mathrm{C}$ atoms in a row).

\section{Conclusions}

Though less stable than the 1,3regioisomer $\mathbf{1 F b}$, the first carbo-mer of 1,4cyclohexadiene $\mathbf{6}$ has been isolated, and characterized. Its relative stability and spectroscopical properties are fully consistent with general principles in the chemistry of $\pi$ - empirical and TDDFT calculations.

In prospect of these advances in the synthesis of trifluoromethylated ring carbomers of 1,3- or 1,4-cyclohexadienes, the synthesis of hexa-trifluoromethyl-carbobenzene, $\mathrm{C}_{18}\left(\mathrm{CF}_{3}\right)_{6}$, appears as a natural challenge. The influence of a crown of six electron-withdrawing $\mathrm{CF}_{3}$ substituents on the macro-aromatic character of a highly $\pi$ electron-rich core is indeed a fundamental issue. Although the present results confirm that this target cannot be accessible by reductive elimination from a hexa(trifluoromethyl)hexaoxy-[6]pericyclyne, alternative strategies and future efforts deserve to be envisaged [11].

\section{Experimental part}

General remarks. THF and dimethoxyethane (DME) were dried and distilled over sodium/benzophenone, dichloromethane (DCM) and pentane over calcium hydride. All others reagents were used as commercially available, particularly solution of $n$-butyllithium were 2.5 $\mathrm{M}$ in hexane, and solution of $\mathrm{HCl}$ were $2 \mathrm{M}$ in $\mathrm{Et}_{2} \mathrm{O}$. All reactions were carried out under argon atmosphere, using Schlenk and vacuum line techniques. Column chromatography was carried out on silica gel (60 Å, C.C 70-200 $\mu \mathrm{m}$ ). Silica gel thin layer chromatography plates $(60 \mathrm{~F} 254,0.25 \mathrm{~mm})$ were revealed by treatment with an ethanolic solution of phosphomolybdic acid $(20 \%)$. The following analytical 
instruments were used: ${ }^{1} \mathrm{H}$ and ${ }^{13} \mathrm{C}$ NMR: Brüker Avance 300 and Avance 400 spectrometers; mass spectroscopy: Quadrupolar Nermag R10-10H spectrometer; IR: PerkinElmer Spectrum 100 FT-IR spectrometer. NMR chemical shifts are given in ppm with positive values to high frequency relative to the tetramethylsilane reference for ${ }^{1} \mathrm{H}$ and ${ }^{13} \mathrm{C}$, and $\mathrm{CCl}_{3} \mathrm{~F}$ reference for ${ }^{19} \mathrm{~F}$. Coupling constants $J$ are in Hertz. Previously described procedures were used for the preparation of 7 [3e].

Experimental procedures and characterizations.

\section{4,7,13,16-tetramethoxy-4,7,13,16-tetraphe-} nyl-1,10-bis(trifluoromethyl)cyclooctadeca-

\section{2,5,8,11,14,17-hexayne-1,10-diol}

8.

[6]Pericyclynedione 7 (0.100 g, $0.146 \mathrm{mmol})$ and $\mathrm{CsF}(0.022 \mathrm{~g}, 0.146 \mathrm{mmol})$ were dried under vacuum in a Schlenk tube. Dry DME (0.2 $\mathrm{mL})$ and $\mathrm{CF}_{3}$-TMS (0.087 $\left.\mathrm{mL}, 0.59 \mathrm{mmol}\right)$ were added and the resulting mixture was stirred under argon overnight. After dilution with $\mathrm{Et}_{2} \mathrm{O}$ $(0.2 \mathrm{~mL})$ and treatment with aqueous $2 \mathrm{M} \mathrm{HCl}$ (2 $\mathrm{mL})$, the mixture was stirred at room temperature for $2.5 \mathrm{~h}$. Water was then added, and the aqueous layer was extracted with $\mathrm{Et}_{2} \mathrm{O}$. The combined organic layers were washed with brine, dried over $\mathrm{MgSO}_{4}$ and concentrated under reduced pressure to give $\mathbf{8}$ as an orange solid (0.089 g, $74 \%)$.

${ }^{1} \mathrm{H}$ NMR $\left(\mathrm{CDCl}_{3}, 400 \mathrm{MHz}\right): \delta=3.25(\mathrm{~m}, 2 \mathrm{H}$, $\mathrm{OH}), 3.35-3.64\left(\mathrm{~m}, 12 \mathrm{H}, \mathrm{OCH}_{3}\right), 7.33-7.42$ (m, $\left.12 \mathrm{H}, m-, p-\mathrm{C}_{6} H_{5}\right), 7.62-7.73\left(\mathrm{~m}, 8 \mathrm{H}, o-\mathrm{C}_{6} H_{5}\right)$;
${ }^{19} \mathrm{~F} \mathrm{NMR}\left(\mathrm{CDCl}_{3}, 282 \mathrm{MHz}\right): \delta=-81.28-(-$ 81.02) (m, CF $\left.F_{3}\right) ;{ }^{13} \mathrm{C}\left\{{ }^{1} \mathrm{H}\right\}$ NMR $\left(\mathrm{CDCl}_{3}, 75\right.$ MHz): $\delta=53.4\left(\mathrm{OCH}_{3}\right), 64.5(\mathrm{q}, J=37 \mathrm{~Hz}, C-$ $\left.\mathrm{CF}_{3}\right), \quad 76.6\left(\mathrm{C}-\mathrm{OCH}_{3}\right), \quad 79.2-79.7, \quad 83.7-84.4$ $(C \equiv C), 121.8\left(\mathrm{q}, \mathrm{J}=285 \mathrm{~Hz}, C \mathrm{~F}_{3}\right), 126.3,128.7$ $\left(o-, m-C_{6} \mathrm{H}_{5}\right), 129.4\left(p-C_{6} \mathrm{H}_{5}\right), 138.2-138.6$ (i$\left.\mathrm{C}_{6} \mathrm{H}_{5}\right)$. HRMS (DCI-CH $)_{4}: \mathrm{m} / z$ calcd for $\mathrm{C}_{48} \mathrm{H}_{34} \mathrm{O}_{6} \mathrm{~F}_{6}$ : 820.2260, found: 820.2255.

\section{4,7,13,16-tetraphenyl-1,10-bis(trifluoro- methyl)cyclooctadeca-4,5,6,13,14,15-hexaen-} 2,8,11,17-tetrayne-1,10-diol 6. To a solution of 8 (0.050 g, $0.061 \mathrm{mmol})$ in DCM (25 mL) under stirring at $-78{ }^{\circ} \mathrm{C}$ were added $\mathrm{SnCl}_{2}(0.116 \mathrm{~g}$, $0.61 \mathrm{mmol})$ and $\mathrm{HCl}(0.61 \mathrm{~mL}, 1.22 \mathrm{mmol})$. The resulting mixture was allowed to warm up to room temperature and stirred overnight, before treatment with $1 \mathrm{M}$ aqueous $\mathrm{NaOH}(1.2 \mathrm{~mL})$. The aqueous layer was extracted with DCM and the combined organic layers were washed with brine, dried over $\mathrm{MgSO}_{4}$. The DCM solution was filtered through a pad of silica and concentrated to dryness. The residue was dissolved in the minimum amount of DCM and a solid was precipitated by addition of pentane. The obtained red-orange powder was finally washed with acetone to give $6(3 \mathrm{mg}, 6 \%)$.

${ }^{1} \mathrm{H}$ NMR (THF-D $\left.8,300 \mathrm{MHz}\right): \delta=7.44-7.55$ $\left(\mathrm{m}, 12 \mathrm{H}, m-, p-\mathrm{C}_{6} H_{5}\right), 7.86-7.88\left(\mathrm{~m}, 8 \mathrm{H}, \mathrm{o}^{-}\right.$ $\left.\mathrm{C}_{6} H_{5}\right) ;{ }^{19} \mathrm{~F}$ NMR (THF-D $\left.8,282 \mathrm{MHz}\right): \delta=-$ $81.21\left(\mathrm{CF}_{3}\right) ;{ }^{13} \mathrm{C}\left\{{ }^{1} \mathrm{H}\right\}$ NMR $\left(\mathrm{THF}-\mathrm{D}_{8}, 75 \mathrm{MHz}\right)$ : $\delta=65.3\left(\mathrm{q}, J=36 \mathrm{~Hz}, C-\mathrm{CF}_{3}\right), 82.1,93.1$ $(C \equiv C), 104.3 \quad\left(=\mathrm{C}=C-\mathrm{C}_{6} \mathrm{H}_{5}\right), 122.6(\mathrm{q}, \mathrm{J}=285$ 
$\left.\mathrm{Hz}, C \mathrm{~F}_{3}\right), 127.2,128.9\left(o-, m-C_{6} \mathrm{H}_{5}\right), 129.7(p-$ $\left.C_{6} \mathrm{H}_{5}\right), 133.6\left(i-C_{6} \mathrm{H}_{5}\right), 150.1(\mathrm{C}=C=C=\mathrm{C}) . \mathrm{MS}$ (MALDI-TOF/DCTB): $m / z: 696.0\left[\mathrm{M}^{+}\right.$. HRMS (MALDI-TOF): $\mathrm{m} / \mathrm{z}$ calcd for $\mathrm{C}_{44} \mathrm{H}_{22} \mathrm{O}_{2} \mathrm{~F}_{6}$ : 696.1548, found: 696.1590. UV $\left(\mathrm{CHCl}_{3}\right): v=$ $418(\varepsilon=73400)$.

Acknowledgments. In addition to the Ministère de l'Enseignement Supérieur de la Recherche et de la Technologie and the Toulouse III-Paul Sabatier University, thanks are due to the Centre National de la Recherche Scientifique and to the ANR (11-BS07-016-01) for the post-doctoral fellowship of A. R.

\section{References}

[1] L. Leroyer, C. Lepetit, A. Rives, V. Maraval, N. Saffon-Merceron, D. Kandaskalov, D. Kieffer, R. Chauvin, Chem.-Eur. J. 2012, 18, 3226-3240.

[2] For references on carbo-mers see: (a) R Chauvin, Tetrahedron Lett. 1995, 397-400; (b) V. Maraval, R. Chauvin, Chem. Rev. 2006, 106, 5317-5343.

[3] For references on [5] and [6]pericyclynes, see: (a) L. T. Scott, G. J. DeCicco, J. L. Hyun, G. Reinhardt, J. Am. Chem. Soc. 1983, 105, 7760-7761; (b) L. T. Scott, G. J. DeCicco, J. L. Hyun, G. Reinhardt, J. Am. Chem. Soc. 1985, 107, 6546-6555; (c) L. Maurette, C. Tedeschi, E. Sermot, M. Soleilhavoup, F. Hussain, B. Donnadieu, R. Chauvin, Tetrahedron 2004, 60, 10077-10098; (d) C. Saccavini, C. Tedeschi, L. Maurette, C. Sui-Seng, C. Zou, M. Soleilhavoup, L. Vendier, R. Chauvin, Chem.-Eur. J. 2007, 13, 4895-4913; (e) L. Leroyer, C. Zou, V. Maraval, R. Chauvin, C. R. Chimie, 2009, 12, 412-419.

[4] For references on carbo-benzenes, see: (a) Y. Kuwatani, N. Watanabe, I. Ueda, Tetrahedron Lett. 1995, 36, 119-122; (b) R. Suzuki, H. Tsukude, N. Watanabe, Y. Kuwatani, I. Ueda, Tetrahedron 1998, 54, 2477-2496; (c)
R. Chauvin, Tetrahedron Lett. 1995, 36, 401-404; (d) C. Saccavini, C. Sui-Seng, L. Maurette, C. Lepetit, S. Soula, C. Zou, B. Donnadieu, R. Chauvin, Chem.-Eur. J. 2007, 13, 4914-4931; (e) C. Zou, C. Duhayon, V. Maraval, R. Chauvin, Angew. Chem. Int. Ed. 2007, 46, 4337-4341; (f) A. Rives, I. Baglai, V. Malytskyi, V. Maraval, N. SaffonMerceron, Z. Voitenko, R. Chauvin, Chem. Commun. 2012, 48, 8763-8765; (g) I. Baglai, V. Maraval, C. Bijani, N. Saffon-Merceron, Z. Voitenko, Y. M. Volovenko, R. Chauvin, Chem. Commun. 2013, 49, 8374-8376.

[5] A. Rives, I. Baglai, C. Barthes, V. Maraval, N. Saffon-Merceron, Z. Voitenko, Y. Volovenko, R. Chauvin, Chem. Sci. 2015, 6, 1139-1149.

[6] V. Maraval, L. Leroyer, A. Harano, C. Barthes, A. Saquet, C. Duhayon, T. Shinmyozu, R. Chauvin, Chem.-Eur. J. 2011, 17, 5086-5100.

[7] (a) H. Cartwright, J. Chem. Educ. 1986, 63, 984987; (b) S. Kreft, M. Kreft, Naturwissenschaften 2007, 94, 935-939.

[8] (a) J.-D. van Loon, P. Seiler, F. Diederich, Angew. Chem. Int. Ed. 1993, 32, 1187-1189; (b) A. Auffrant, F. Diederich, C. Boudon, J.-P. Gisselbrecht, M. Gross, Helv. Chim. Acta, 2004, 87, 3085-3105; (c) A. Auffrant, B. Jaun, P. D. Jarowski, K. N. Houk, F. Diederich, Chem.-Eur. J. 2004, 10, 2906-2911; (d) L. Leroyer, V. Maraval, R. Chauvin, Chem. Rev. 2012, 112, 1310-1343.

[9] (a) R. P. Singh, G. Cao, R. L. Kirchmeier, J. M. Shreeve, J. Org. Chem. 1999, 64, 2873-2876; (b) J. Simon, T. T. Nguyen, E. Chelain, N. Lensen, J. Pytkowicz, G. Chaume, T. Brigaud, Tetrahedron: Asymm. 2011, 22, 309-314 ; (c) J. Simon, E. Chelain, T. Brigaud, Org. Lett. 2012, 14, 604-607 ; (c) A. Fleury, E. Chelain, T. Brigaud, manuscript in preparation.

[10] A. Rives, V. Maraval, N. Saffon-Merceron, R. Chauvin, Chem.-Eur. J. 2014, 20, 483-492.

[11] K. Black, A. Rives, C. Barthes, E. Chelain, T. Brigaud, V. Maraval, R. Chauvin, unpublished results. 